Article

\title{
Optimization of the Oxidation Behavior and Mechanical Properties by Designing the $\mathrm{TiB}_{2} / \mathrm{ZrO}_{2}$ Multilayers
}

\author{
Dong Mao ${ }^{1,2}$, Yang Xu ${ }^{1,2}$, Lei Dong ${ }^{1,2, *}$, Jie $\mathrm{Wu}^{1,2}$, Mengli Zhao ${ }^{1,2}$ and Dejun Li ${ }^{1,2, *}$ \\ 1 College of Physics and Materials Science, Tianjin Normal University, Tianjin 300387, China; \\ guozheng@tjnu.edu.cn (D.M.); ldong@tjnu.edu.cn (Y.X.); jiewu@tjnu.edu.cn (J.W.); \\ zml0506@tjnu.edu.cn (M.Z.) \\ 2 Tianjin International Joint Research Center of Surface Technology for Energy Storage Materials, Tianjin \\ Normal University, Tianjin 300387, China \\ * Correspondence: dlei0008@tjnu.edu.cn (L.D.); dejunli@tjnu.edu.cn (D.L.); Tel.: +86-22-2376-6519 (D.L.)
}

Received: 31 August 2019; Accepted: 21 September 2019; Published: 23 September 2019

\begin{abstract}
TiB}_{2} / \mathrm{ZrO}_{2}$ multilayers with different modulation ratios (at a fixed modulation period of 50 $\mathrm{nm}$ ) ranging from 2:1 to 6:1 were deposited by magnetron sputtering. The oxidation behavior of the as-deposited multilayers was investigated at $600{ }^{\circ} \mathrm{C}$ in air. The microstructures, mechanical properties, and oxidation resistance of the multilayers were analyzed and compared. The results indicate that discontinuous oxidation retarded the inward diffusion of oxygen and the outward diffusion of metallic components. The formation of dense ( $\mathrm{Ti}, \mathrm{B}$ )-oxide scale and internally inserted $\mathrm{ZrO}_{2}$ layers in the $\mathrm{TiB}_{2} / \mathrm{ZrO}_{2}$ multilayers enhanced the oxidation resistance. Moreover, the oxidation resistance of the multilayers increased as modulation ratio decreased. The hardness and elastic modulus of the $\mathrm{TiB}_{2} / \mathrm{ZrO}_{2}$ multilayers were maximized (23.9 and $303.1 \mathrm{GPa}$, respectively) at the modulation ratio of 6:1. After annealing, the formation of thick $\mathrm{ZrO}_{2}$ layers did not lead to sustained increases in hardness. The maximum hardness and elastic modulus were obtained at the critical modulation ratio of 4:1, and good adhesion strength with the substrate was also observed. The oxidation mechanism and experimental results demonstrate that controlling the modulation ratio of multilayers can produce synergetic enhancements in the oxidation resistance and mechanical properties of multilayers after high-temperature oxidation.
\end{abstract}

Keywords: $\mathrm{TiB}_{2} / \mathrm{ZrO}_{2}$ multilayers; modulation ratio; oxidation resistance; mechanical properties

\section{Introduction}

The development of industry has generated increased demand for coatings with outstanding mechanical properties and oxidation resistance at high temperature for use in cutting tools and microelectronics [1,2]. $\mathrm{TiB}_{2}$ coatings have been widely used due to their high melting point, high hardness, good wear resistance, excellent corrosion resistance, and good thermal conductivity. However, transition metal boride ceramics, which belong to the class of non-oxide coatings, are prone to oxidation, especially at high temperature, which limits their application at high temperatures [3-6]. Considering the harsh environments to which protective coatings are exposed, it is particularly important to improve their oxidation resistance as a protective function. The incorporation of other materials might modify the microstructure of $\mathrm{TiB}_{2}$ to further improve oxidation resistance. As an incorporated material, $\mathrm{ZrO}_{2}$ was chosen in this study, because it has widespread applications in thermal barrier coatings due to its low thermal conductivity and high thermal stability [7-11].

Many surface modification techniques such as thermal spraying [12], laser cladding [13], ion implantation [14], and double-glow plasma surface alloying [15], have been adopted to enhance the 
high-temperature oxidation resistance of substrates. These methods can improve the thermal oxidation resistance of substrates to some extent. However, they suffer various drawbacks, such as poor adhesion, large thermally affected zones, complex processing steps, and high cost, which limit their application. Magnetron sputtering possesses the advantages of preparing dense and uniform coatings with strong adhesion to the substrate. The composition and microstructure of the coating can be controlled by adjusting the sputtering parameters $[16,17]$. Multilayers prepared by magnetron sputtering not only combine the advantages of the different constituent materials but also have better performance and microstructure compared to single layers of their respective components due to the superhardness effect, quantum effects, and macro-tunneling effects between the nanolayers [18-22]. In addition to resulting in excellent mechanical properties, the formation of multilayer structures can also improve the oxidation resistance at high temperatures through limited intermixing [23-25]. $\mathrm{TiB}_{2}$ has a higher hardness ( 34.0 GPa) than $\mathrm{ZrO}_{2}(\sim 11.8 \mathrm{GPa})$, and can thus effectively improve the mechanical properties of multilayers. Inserting $\mathrm{ZrO}_{2}$ layers can also solve the problem of poor high-temperature oxidation resistance that afflicts boride coatings intended to withstand high-speed cutting tools. Unlike the small modulation periods used in past studies, a larger modulation period $(50 \mathrm{~nm})$ is expected to maximize the performances of the two component materials, resulting in outstanding mechanical properties and oxidation resistance.

In this study, $\mathrm{TiB}_{2}$ and $\mathrm{ZrO}_{2}$ monolayers and $\mathrm{TiB}_{2} / \mathrm{ZrO}_{2}$ multilayers with the same modulation periods $(50 \mathrm{~nm})$ and various modulation ratios $\left(t_{\mathrm{TiB}_{2}}: t_{\mathrm{ZrO}_{2}}=2: 1\right.$ to $\left.6: 1\right)$ were synthesized on silicon wafer substrates via magnetron sputtering. The high-temperature oxidation resistance of the samples was studied by thermogravimetric analysis at $600^{\circ} \mathrm{C}$ in air and the effects of structural variation on the multilayer properties were evaluated. Finally, the relationships between microstructural features, chemical components, oxidation resistance, and mechanical performance were established in order to aid practical applications of multilayers in machining.

\section{Experimental Details}

$\mathrm{TiB}_{2} / \mathrm{ZrO}_{2}$ multilayers along with $\mathrm{TiB}_{2}$ and $\mathrm{ZrO}_{2}$ monolayers were prepared using an FJL560CI2 magnetron sputtering system (SKY, Shenyang, China). The high-purity $(99 \%) \mathrm{TiB}_{2}$ and $\mathrm{ZrO}_{2}$ targets were controlled by three radio-frequency $(\mathrm{RF})$ cathodes. When the base pressure of the system was less than $3 \times 10^{-4} \mathrm{~Pa}$, high-purity Ar gas (99.999\%) at a pressure of $0.5 \mathrm{~Pa}$ was introduced into the chamber. Multilayers were deposited by rotating the sample holder, alternately exposing the substrates to the $\mathrm{TiB}_{2}$ and $\mathrm{ZrO}_{2}$ targets. The RF modes were 120 and $80 \mathrm{~W}$ with a constant substrate bias of $-40 \mathrm{~V}$ and a working pressure of $0.5 \mathrm{~Pa}$. The modulation period of each sample was $50 \mathrm{~nm}$, which was corresponded to 20 cycles, after which the top layers of all samples were $\mathrm{TiB}_{2}$. By changing the sputtering time of the $\mathrm{TiB}_{2}$ and $\mathrm{ZrO}_{2}$ targets, thereby changing the thicknesses of the $\mathrm{TiB}_{2}$ and $\mathrm{ZrO}_{2}$ layers, a series of $\mathrm{TiB}_{2} / \mathrm{ZrO}_{2}$ multilayers with different modulation ratios $\left(t_{\mathrm{TiB}_{2}}: t_{\mathrm{ZrO}_{2}}=2: 1,3: 1,4: 1,5: 1\right.$, and 6:1) was obtained. Total thickness of the multilayers was around $900-1000 \mathrm{~nm}$.

Sample crystallinity was analyzed by X-ray diffraction (XRD, D8A, Bruker, Germany) using a D/MAX 2500 diffractometer operated with $\mathrm{Cu} \mathrm{K} \alpha$ radiation at $1.54056 \AA$ in the range of $20^{\circ}-80^{\circ}$. The step size and dwell time of $\theta-2 \theta$ were $0.02^{\circ}$ and $7.76 \mathrm{~s}$, respectively. Confocal Raman spectrometry (Horiba Jobin Yvon, LabRAM HR800, 17 mW, 514 nm, He-Ne laser, France) was used to determine the multilayer phase. Sample morphology was observed by scanning electron microscopy (SEM, TDCLS-8010, Hitachi, Japan) and transmission electron microscopy (TEM, JEOL JEM-3000F, Tokyo, Japan). The operation voltage of TEM is $300 \mathrm{KV}$. The hardness and elastic modulus of the multilayers were measured using a Nano Indenter system (STEP6, Anton Paar, Graz, Austria). The maximum indention depth for all samples was kept at $15 \%$ of the coating thickness to minimize the substrate effects. This system was also used to perform nano-scratch tests. The residual stress $(\sigma)$ of the multilayers was calculated by the Stoney formula [26]: $\sigma=\frac{E_{\mathrm{s}} t_{\mathrm{s}}^{2}}{6 t_{\mathrm{c}}\left(1-v_{\mathrm{s}}\right)}$, in which $E_{\mathrm{s}}, t_{\mathrm{s}}$ and $v_{\mathrm{s}}$ are elastic modulus $(165.6 \mathrm{GPa})$, thickness $(0.4 \mathrm{~mm})$ and Poisson's ratio $(0.18)$ of the substrate respectively; $t_{\mathrm{c}}$ is the multilayer thickness; $R$ is the radius of the curvature of the multilayer coated on substrate, 
which was determined by the multilayer curvature using a surface profilometer (Ambios XP-2, Ambios Technology, California, USA). The oxidation process was conducted in air inside a chamber furnace at $600{ }^{\circ} \mathrm{C}$ for $1 \mathrm{~h}$. The oxidation weight gain of the samples was measured using an electronic analytical balance (XSE, Mettler Toledo, Columbus, OH, USA) with an accuracy of $10^{-8} \mathrm{~kg}$.

\section{Results and Discussion}

\subsection{Microstructure and Crystallographic Characterization before and after Annealing in Air}

Figure 1a shows the XRD patterns of the $\mathrm{TiB}_{2}$ and $\mathrm{ZrO}_{2}$ monolayers along with the $\mathrm{TiB}_{2} / \mathrm{ZrO}_{2}$ multilayers with different $t_{\mathrm{TiB}_{2}}: t_{\mathrm{ZrO}_{2}}$ before annealing. The $\mathrm{TiB}_{2}$ layer presented a weak (100) and (101) texture of $\mathrm{h}-\mathrm{TiB}_{2}$, and the $\mathrm{ZrO}_{2}$ layer existed (111) preferred orientation. In all multilayers, the main diffraction peaks indicate a hexagonal phase of $\mathrm{TiB}_{2}$ and a monoclinic phase of $\mathrm{ZrO}_{2}\left(\mathrm{~m}-\mathrm{ZrO}_{2}\right)$. The peaks in the XRD spectra of the multilayers correspond to the (100) and (101) planes of $\mathrm{TiB}_{2}$ and the (111) and (020) planes of $\mathrm{m}-\mathrm{ZrO}_{2}$. Among the $\mathrm{TiB}_{2} / \mathrm{ZrO}_{2}$ multilayers, the peak intensity was lowest for $t_{\mathrm{TiB}_{2}}: t_{\mathrm{ZrO}_{2}}=4: 1$. Due to the nucleation mechanism was satisfied, the grain growth was controlled by mutual inhibition during the growth process, which also conformed to the principle that the surface energy tends to the minimum [27].
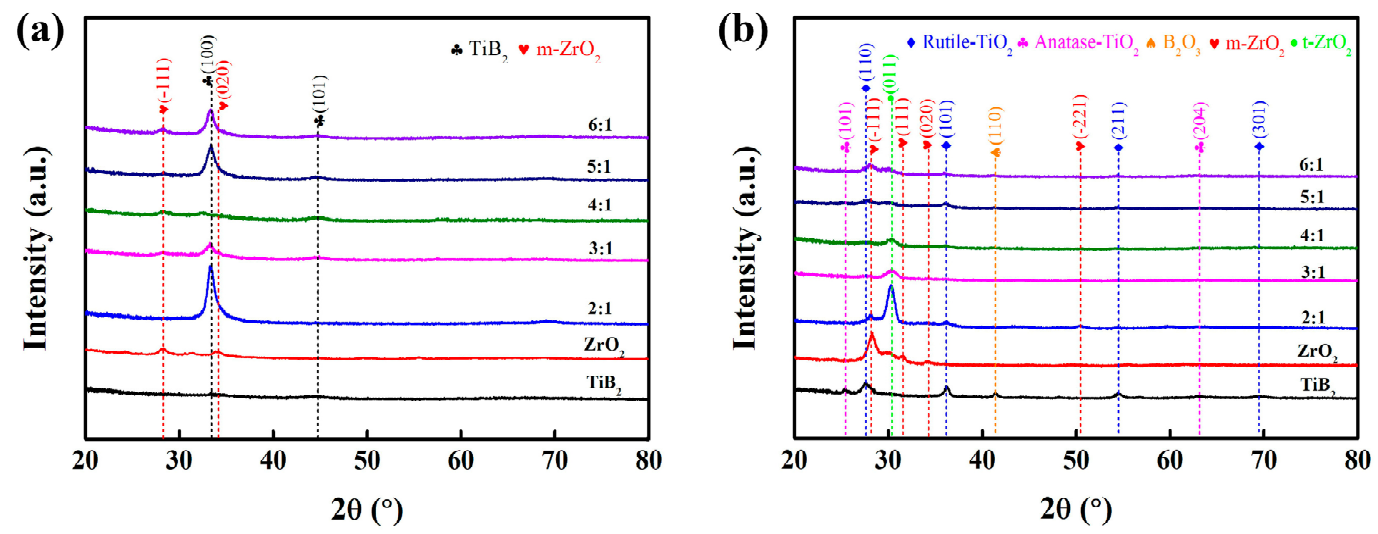

Figure 1. The XRD patterns of the $\mathrm{TiB}_{2}$ and $\mathrm{ZrO}_{2}$ monolayers along with the $\mathrm{TiB}_{2} / \mathrm{ZrO}_{2}$ multilayers with different $t_{\mathrm{TiB}_{2}}: t_{\mathrm{ZrO}_{2}}$ before (a) and after annealing at $600{ }^{\circ} \mathrm{C}$ for $1 \mathrm{~h}(\mathbf{b})$.

Figure $1 \mathrm{~b}$ shows the $\mathrm{XRD}$ patterns of all samples after oxidation. For the $\mathrm{TiB}_{2}$ monolayer, the main phases indicated in the XRD pattern are anatase $\mathrm{TiO}_{2}$ (JCPDF\#21-1272) and rutile $\mathrm{TiO}_{2}$ (JCPDF\#21-1276). For the $\mathrm{ZrO}_{2}$ monolayer, the main phases are $\mathrm{m}-\mathrm{ZrO}_{2}$ (JCPDF\#37-1484) and tetragonal $\mathrm{ZrO}_{2}\left(\mathrm{t}-\mathrm{ZrO}_{2}\right)$ (JCPDF\#50-1089). Only $\mathrm{TiO}_{2}, \mathrm{~m}-\mathrm{ZrO}_{2}$ and $\mathrm{t}-\mathrm{ZrO}_{2}$ appear in the $\mathrm{TiB}_{2} / \mathrm{ZrO}_{2}$ multilayers irrespective of the value of $t_{\mathrm{TiB}_{2}}: t_{\mathrm{ZrO}_{2}}$, while no $\mathrm{TiB}_{2}$ is detected. This could suggest severe oxidation of the $\mathrm{TiB}_{2}$ layers in the multilayers. The nucleation mechanism also was applied to oxidized films, the $\mathrm{TiB}_{2} / \mathrm{ZrO}_{2}$ multilayer with $t_{\mathrm{TiB}_{2}}: t_{\mathrm{ZrO}_{2}}=4: 1$ had the lowest peak intensity. Meanwhile, the intensities of $\mathrm{t}-\mathrm{ZrO}_{2}$ increased and those of $\mathrm{m}-\mathrm{ZrO}_{2}$ decreased in the multilayer spectra, which means that oxidation promotes the growth of the high-temperature tetragonal phase of $\mathrm{ZrO}_{2}$ grains.

Figure 2 shows the surface and cross-sectional SEM images of the $\mathrm{TiB}_{2}$ monolayers and $\mathrm{TiB}_{2} / \mathrm{ZrO}_{2}$ multilayers $\left(t_{\mathrm{TiB}_{2}}: t_{\mathrm{ZrO}_{2}}=2: 1,4: 1\right.$, and 6:1) on Si substrates after annealing in air at $600^{\circ} \mathrm{C}$ for $1 \mathrm{~h}$. The $\mathrm{TiB}_{2}$ monolayer showed large pompon-like (Ti, B)-oxides (Figure 2a). The surface SEM images of the $\mathrm{TiB}_{2} / \mathrm{ZrO}_{2}$ multilayers were similar for all values of $t_{\mathrm{TiB}_{2}}: t_{\mathrm{ZrO}_{2}}$ (Figure $2 \mathrm{~b}-\mathrm{d}$ ). All samples displayed sphere-like oxide microstructures. As $t_{\mathrm{TiB}_{2}}: t_{\mathrm{ZrO}_{2}}$ increased, oxygen diffused toward the inner regions of the $\mathrm{TiB}_{2} / \mathrm{ZrO}_{2}$ multilayers, leading to the formation of porous scaly deposit of (Ti, B)-oxide. The cross-sectional SEM images of the $\mathrm{TiB}_{2} / \mathrm{ZrO}_{2}$ multilayers indicate that the compact (Ti, B)-oxide scale became thicker as $t_{\mathrm{TiB}_{2}}: t_{\mathrm{ZrO}_{2}}$ increased. The $\mathrm{ZrO}_{2}$ layers were thinner in the $\mathrm{TiB}_{2} / \mathrm{ZrO}_{2}$ multilayers with $t_{\mathrm{TiB}_{2}}: t_{\mathrm{ZrO}_{2}}=6: 1$ compared to those with $t_{\mathrm{TiB}_{2}}: t_{\mathrm{ZrO}_{2}}=2: 1$ and 4:1, resulting in decreased oxidation resistance at $t_{\mathrm{TiB}_{2}}: t_{\mathrm{ZrO}_{2}}=6: 1$. That is, while the $\mathrm{TiB}_{2} / \mathrm{ZrO}_{2}$ multilayers are in their initial oxidation state, 
the thick $\mathrm{ZrO}_{2}$ layers effectively delayed the inward diffusion of oxygen and impeded the outward diffusion of metal atoms (Figure $2 \mathrm{f}-\mathrm{h}$ ). In contrast, the $\mathrm{TiB}_{2}$ monolayer was almost completely oxidized, as shown in Figure 2e. The multilayered architecture clearly resulted in the compression of crystal grains and hindered grain growth, leading to the formation of a dense oxide layer that suppressed further oxidation. Moreover, $\mathrm{ZrO}_{2}$ blocked the progress of the oxidation layer by layer, improving the overall oxidation resistance of the multilayer.

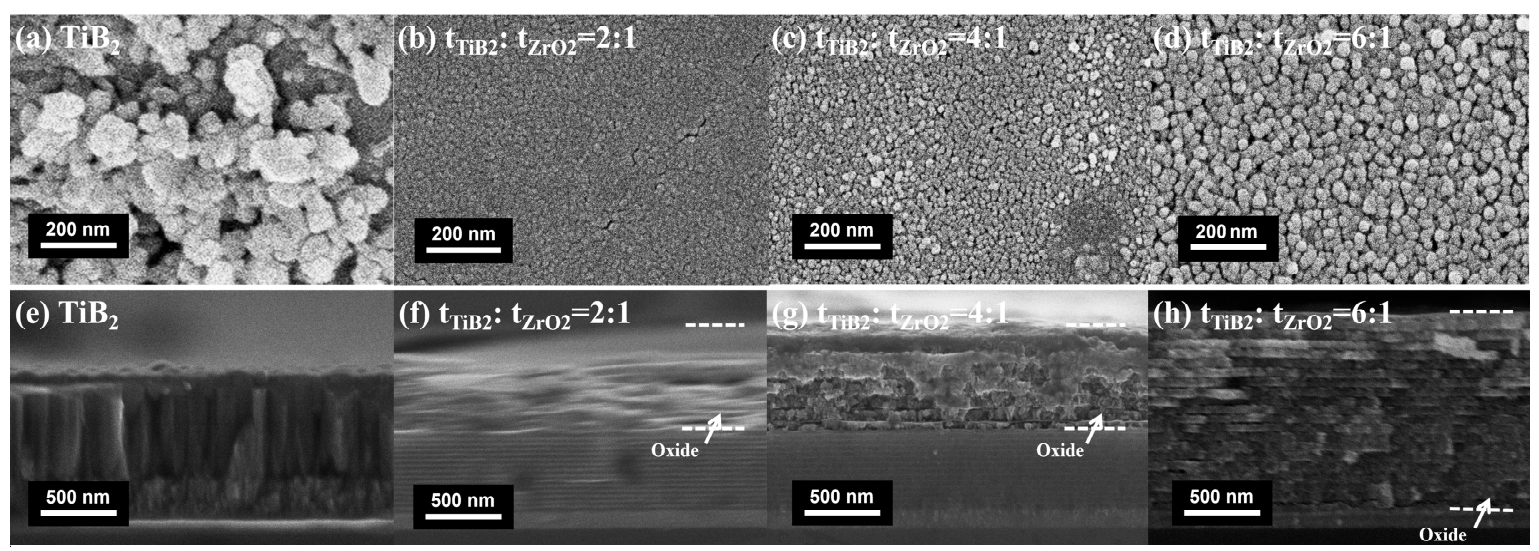

Figure 2. The surface and cross-sectional SEM images of the $\mathrm{TiB}_{2}$ monolayers $(\mathbf{a}, \mathbf{e})$, and $\mathrm{TiB}_{2} / \mathrm{ZrO}_{2}$ multilayers with $t_{\mathrm{TiB}_{2}}: t_{\mathrm{ZrO}_{2}}=2: 1(\mathbf{b}, \mathbf{f}), t_{\mathrm{TiB}_{2}}: t_{\mathrm{ZrO}_{2}}=4: 1(\mathbf{c}, \mathbf{g})$ and $t_{\mathrm{TiB}_{2}}: t_{\mathrm{ZrO}_{2}}=6: 1(\mathbf{d}, \mathbf{h})$ after annealing in air at $600{ }^{\circ} \mathrm{C}$ for $1 \mathrm{~h}$.

Figure 3 shows cross-sectional high-resolution TEM (HRTEM) images and the corresponding selected-area electron diffraction (SAED) patterns of $\mathrm{TiB}_{2} / \mathrm{ZrO}_{2}$ multilayers with $t_{\mathrm{TiB}_{2}}: \mathrm{ZrO}_{\mathrm{Zr}_{2}}=4: 1$ before and after annealing at $600{ }^{\circ} \mathrm{C}$ for $1 \mathrm{~h}$. Both pre- and post-annealing, the images exhibited a clearly periodic multilayered structure. The diffraction rings in the inset SAED pattern of Figure 3a are characteristic of the (101) and (111) planes and can be indexed to the hexagonal structure of $\mathrm{TiB}_{2}$ and the monoclinic structure of $\mathrm{ZrO}_{2}$. The diffraction rings in the SAED pattern in Figure $3 b$ correspond to the (111), and (011), and (110), (012), (211) planes and can be indexed to the monoclinic and tetragonal structures of $\mathrm{ZrO}_{2}$ along with the rutile structure of $\mathrm{TiO}_{2}$. These results are consistent with the qualitative information provided by XRD. The HRTEM micrographs show the well-formed crystal state of the multilayers before and after annealing. The modulation period $(\Lambda)$ of the multilayers showed an appreciable increase after annealing due to the increase in grain size and the difference in molar volumes between the oxidation products. For example, the modulation periods estimated from the TEM images at the same position before and after annealing were approximately 49.6 and $52.1 \mathrm{~nm}$, respectively. The single-layer thicknesses of the $\mathrm{TiB}_{2}$, (Ti, B)-oxide, and $\mathrm{ZrO}_{2}$ layers were approximately 39.7, 42.8, and $9 \mathrm{~nm}$, respectively. In summary, the barriers formed by the $\mathrm{ZrO}_{2}$ layers effectively blocked oxygen from entering during oxidation, helping maintain the multilayered structure. The generation of the high-temperature tetragonal phase of $\mathrm{ZrO}_{2}$ after oxidation, as demonstrated by the SAED pattern in Figure 3b, was also favorable for the oxidation resistance of the multilayers.

The Raman spectra of the multilayers after annealing for different times at $600{ }^{\circ} \mathrm{C}$ in air are shown in Figure 4. After 30 min of oxidation (Figure 4a), peaks corresponding to $\mathrm{ZrO}_{2}\left(315 \mathrm{~cm}^{-1}\right), \mathrm{TiO}_{2}$ (445 and $\left.515 \mathrm{~cm}^{-1}\right)$, and $\mathrm{TiB}_{2}\left(590 \mathrm{~cm}^{-1}\right)$ along with weak peaks of $\mathrm{B}_{2} \mathrm{O}_{3}\left(1120,1120\right.$, and $1420 \mathrm{~cm}^{-1}$ ) appeared in the multilayer spectrum. When the oxidation time increased to $60 \mathrm{~min}$ (Figure $4 \mathrm{~b}$ ), the intensities of the $\mathrm{TiO}_{2}$ peaks at 445 and $515 \mathrm{~cm}^{-1}$ increased, while that of the $\mathrm{TiB}_{2}$ peak decreased, and $\mathrm{TiO}_{2}$ peaks appeared at 395, 638, and $826 \mathrm{~cm}^{-1}$ [28-31]. After annealing for $90 \mathrm{~min}$ (Figure 4c), the intensities of the $\mathrm{TiO}_{2}$ and $\mathrm{B}_{2} \mathrm{O}_{3}$ peaks increased, and the $\mathrm{TiB}_{2}$ peak disappeared. Compared to the $\mathrm{TiB}_{2} / \mathrm{ZrO}_{2}$ multilayers (Figure $4 \mathrm{~d}$ ), the intensities of the $\mathrm{TiO}_{2}$ and $\mathrm{B}_{2} \mathrm{O}_{3}$ peaks were much higher for the $\mathrm{TiB}_{2}$ monolayers after $60 \mathrm{~min}$ of oxidization, indicating that surface oxidation was more serious in the $\mathrm{TiB}_{2}$ monolayers. 

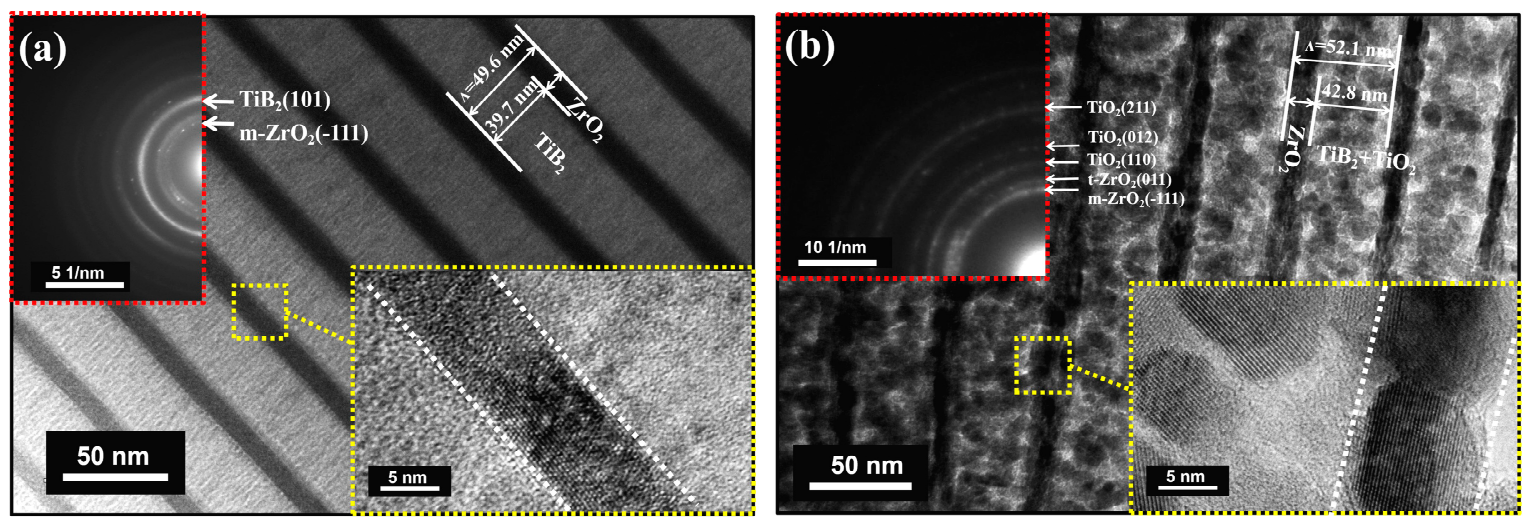

Figure 3. Cross-sectional HRTEM images and the corresponding SAED patterns of $\mathrm{TiB}_{2} / \mathrm{ZrO}_{2}\left(t_{\mathrm{TiB}_{2}}: t_{\mathrm{ZrO}_{2}}\right.$ $=4: 1$ ) multilayers before (a) and after annealing at $600{ }^{\circ} \mathrm{C}$ for $1 \mathrm{~h}(\mathbf{b})$.

(a)

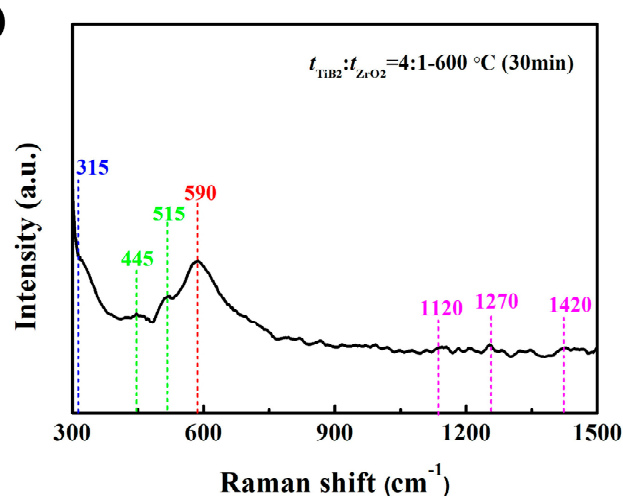

(c)

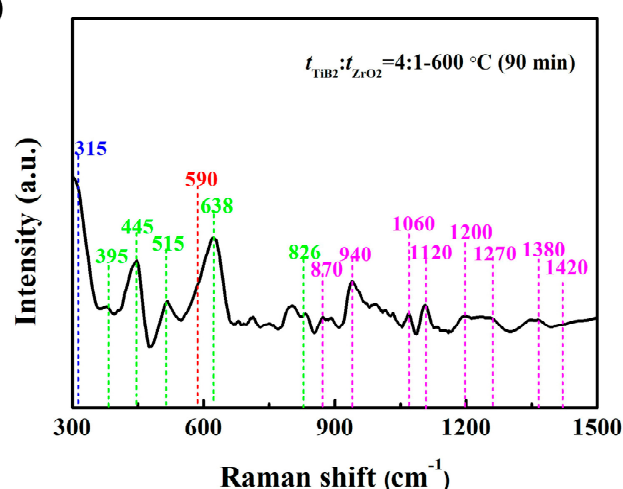

(b)

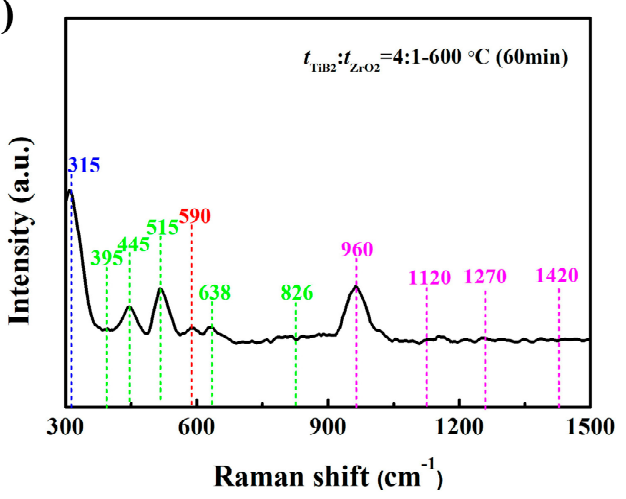

(d)

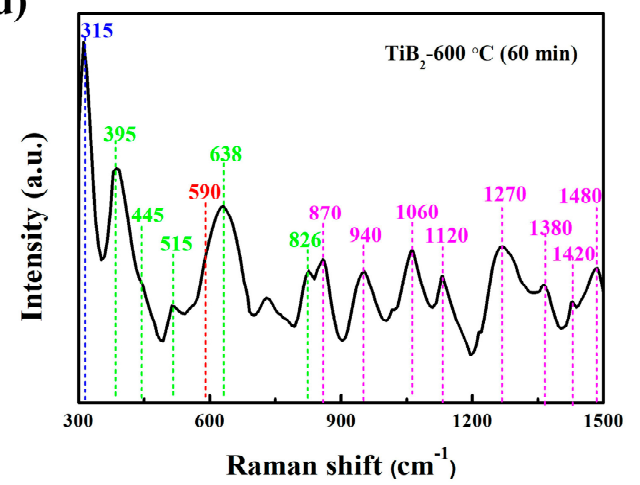

Figure 4. The Raman spectra of theTiB $2 / \mathrm{ZrO}_{2}\left(t_{\mathrm{TiB}_{2}}: t_{\mathrm{ZrO}_{2}}=4: 1\right)$ multilayers after annealing for (a) $30 \mathrm{~min}$, (b) $60 \mathrm{~min}$, (c) $90 \mathrm{~min}$, and $\mathrm{TiB}_{2}$ monolayers after $60 \mathrm{~min}$ of oxidization (d).

\subsection{Mechanism of Improved Oxidation Resistance and Mechanical Properties}

Based on the XRD, SEM, TEM, and Raman results, high-temperature oxidation led to changes in the structure and composition of the $\mathrm{TiB}_{2} / \mathrm{ZrO}_{2}$ multilayers. To clarify the effects of high-temperature oxidation on the multilayer properties, the oxidation mechanism is depicted in Figure 5. The $\mathrm{TiB}_{2} / \mathrm{ZrO}_{2}$ multilayers were oxidized to form $\mathrm{TiO}_{2}$ and $\mathrm{B}_{2} \mathrm{O}_{3}$ on the surfaces of the multilayers. As the oxidation time increased, the oxide content gradually increased. The primary oxidation reaction can be written as follows [32]. 


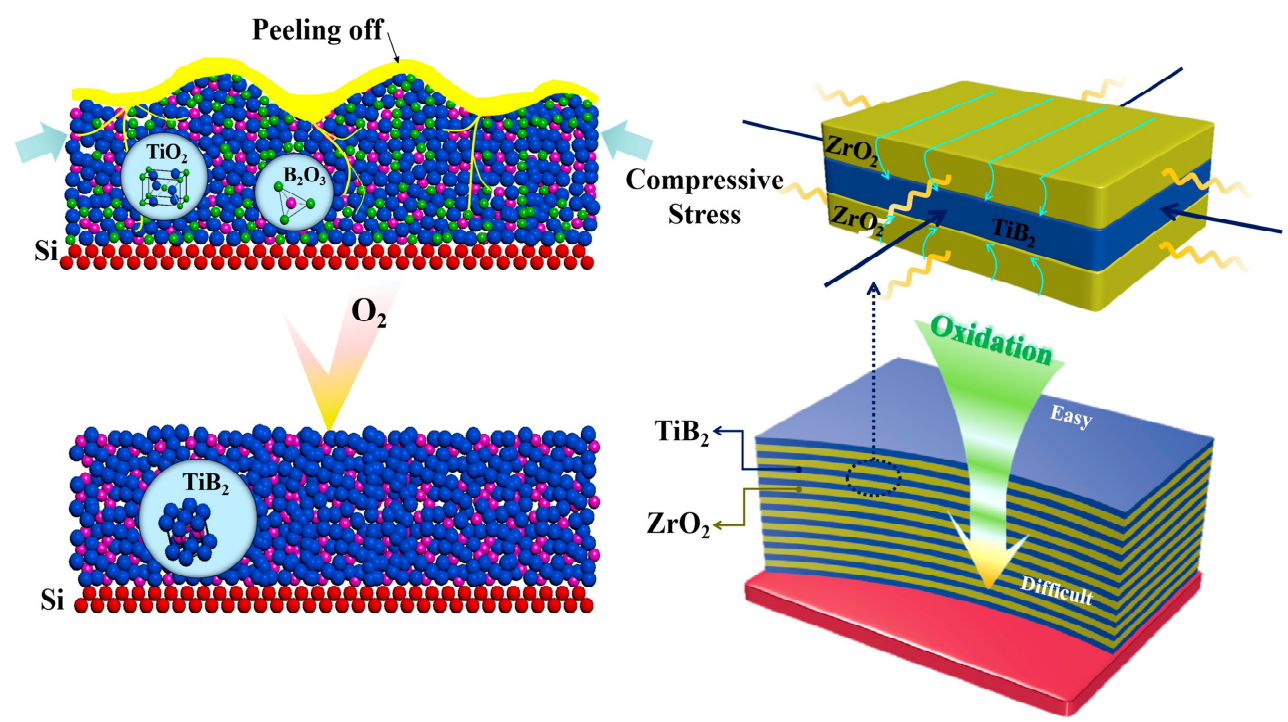

Figure 5. The oxidation mechanism of $\mathrm{TiB}_{2}$ monolayer and $\mathrm{TiB}_{2} / \mathrm{ZrO}_{2}$ multilayer.

$$
\mathrm{TiB}_{2}(\mathrm{~s})+\frac{5}{2} \mathrm{O}_{2}(\mathrm{~g})=\mathrm{TiO}_{2}(\mathrm{~s})+\mathrm{B}_{2} \mathrm{O}_{3}(\mathrm{~s})
$$

According to thermodynamic calculation, the standard Gibbs free energy of the reaction in Equation (1) is negative at $600{ }^{\circ} \mathrm{C}$, indicating that the formation of $\mathrm{TiO}_{2}$ and $\mathrm{B}_{2} \mathrm{O}_{3}$ phases is feasible. In the $\mathrm{TiB}_{2}$ monolayer, the oxygen atoms entering the monolayer through the inter-crystal gaps can react with $\mathrm{TiB}_{2}$ to form $\mathrm{TiO}_{2}$ and $\mathrm{B}_{2} \mathrm{O}_{3}$, releasing the residual stress in the monolayer. The $\mathrm{TiB}_{2}$ monolayer expands after annealing due to the different molar volumes of $\mathrm{TiB}_{2}\left(15.5 \mathrm{~cm}^{3} / \mathrm{mol}\right), \mathrm{TiO}_{2}\left(18.8 \mathrm{~cm}^{3} / \mathrm{mol}\right)$, and $\mathrm{B}_{2} \mathrm{O}_{3}\left(38.7 \mathrm{~cm}^{3} / \mathrm{mol}\right)$, and then strip from the substrate. In addition, due to the difference in the thermal expansion coefficient between the $\mathrm{TiB}_{2}$ monolayer and the substrate, circular blisters form as a result of the biaxial compressive stress generated during heating. Once cracks form at the edges of the blisters, circular peeling occurs [33]. In the multilayers, the formation of circular blisters in the $\mathrm{TiB}_{2}$ phase is obstructed due to the presence of internal interfaces. For $\mathrm{ZrO}_{2}$, its thermal conductivity varies widely and almost continuously throughout the sample, so the $\mathrm{ZrO}_{2}$ layers are hardly oxidized at all. Therefore, they form barriers hindering the oxidation process. This discontinuous oxidation of the multilayers is key to improving their oxidation resistance. Meanwhile, $\mathrm{ZrO}_{2}$ has an elastic modulus of approximately $50 \mathrm{GPa}$ and can form an alternating soft and hard multilayer system with $\mathrm{TiB}_{2}[34,35]$. The plastic deformation of the $\mathrm{ZrO}_{2}$ layers allows the partial relief of residual stress generated by the volumetric expansion of the $\mathrm{TiB}_{2}$ layers upon oxidation [1]. This mechanism contributes to the observed increase in hardness with increasing $\mathrm{ZrO}_{2}$ layer thickness because the development of compressive stress in the $\mathrm{ZrO}_{2}$ layers can accommodate the volume increase of the $\mathrm{TiB}_{2}$ layers during oxidation.

Further experiments were carried out to verify the above oxidation mechanism. Figure 6a shows the thermogravimetric curves of the $\mathrm{TiB}_{2}$ and $\mathrm{ZrO}_{2}$ monolayers and the $\mathrm{TiB}_{2} / \mathrm{ZrO}_{2}$ multilayers during oxidation. Here, mass gain was defined as the mass change of the specimen per unit area corresponding to the as-deposited multilayers after annealing. After oxidation at $600{ }^{\circ} \mathrm{C}$, the $\mathrm{TiB}_{2}$ monolayers exhibited an obvious mass gain, while the $\mathrm{ZrO}_{2}$ monolayers hardly gained any mass. With increasing modulation ratio, the mass gain of the $\mathrm{TiB}_{2} / \mathrm{ZrO}_{2}$ multilayers also increased. For all multilayers, the mass gain during oxidation was lower than that of the $\mathrm{TiB}_{2}$ monolayer, indicating that the multilayered structure of the $\mathrm{TiB}_{2} / \mathrm{ZrO}_{2}$ multilayers is favorable for improving oxidation resistance. The $\mathrm{TiB}_{2}$ and $\mathrm{ZrO}_{2}$ monolayers along with the $\mathrm{TiB}_{2} / \mathrm{ZrO}_{2}$ multilayers exhibited parabolic mass gains during oxidation, indicating that the oxidation rate of the $\mathrm{TiB}_{2} / \mathrm{ZrO}_{2}$ multilayers follows a diffusion-controlled law [36,37]. 


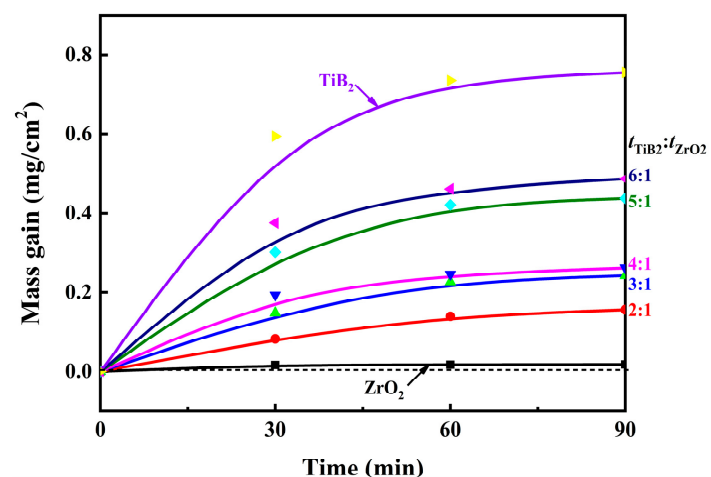

(a)

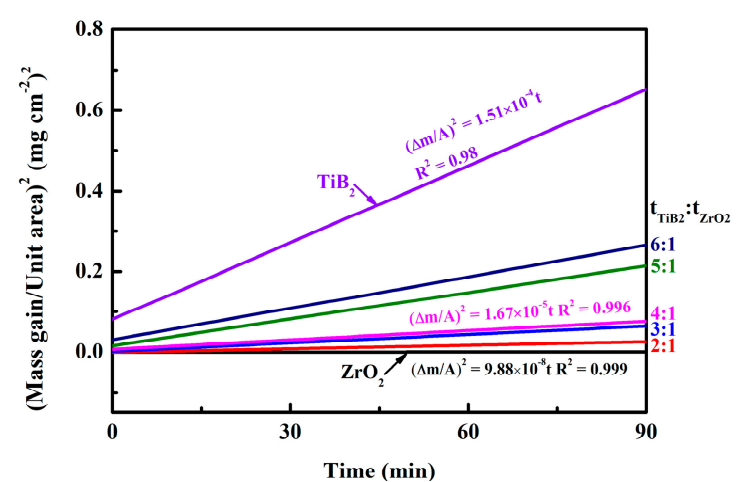

(b)

Figure 6. (a) The thermogravimetric curves and (b) the plots of $(\Delta m / A)^{2}$ versus time of the $\mathrm{TiB}_{2}$ and $\mathrm{ZrO}_{2}$ monolayers and the $\mathrm{TiB}_{2} / \mathrm{ZrO}_{2}$ multilayers during oxidation.

The parabolic oxidation rate can be expressed by Equation (2):

$$
\left(\frac{\Delta m}{A}\right)^{2}=k t+c
$$

where $t$ is the time, $\Delta m$ is the mass change, $A$ is the surface area of the sample, $k$ is the parabolic rate constant, and $c$ is a constant.

Figure $6 \mathrm{~b}$ shows plots of $(\Delta m / A)^{2}$ vs. $t$ with linear fits to the data. Evidently, the data points can be fitted to straight lines. All curves obey the parabolic law, indicating that the oxidation reaction was controlled by diffusion. The coefficients of determination $\left(R^{2}\right)$ were in the range of $0.98-0.99$, indicating that the data were well fit by straight lines. The values of $k$ are shown in Table 1 . The activation energies of the multilayers were calculated using the Arrhenius equation (Equation (3)):

$$
k=A_{0} \exp \left(\frac{E_{\mathrm{a}}}{R T}\right)
$$

where $T$ is the absolute temperature, $R$ is the gas constant, $A_{0}$ is the pre-exponential constant, and $E_{\mathrm{a}}$ is the activation energy, which can be calculated from Equation (4):

$$
\operatorname{In} k=\operatorname{In} A_{0}-\frac{E_{\mathrm{a}}}{R T}
$$

Table 1. The calculated $K, R^{2}$ and $E_{\mathrm{a}}$ (activation energy) values of $\mathrm{TiB}_{2}, \mathrm{ZrO}_{2}$ monolayers and $\mathrm{TiB}_{2} / \mathrm{ZrO}_{2}$ multilayers tested at $600^{\circ} \mathrm{C}$, respectively.

\begin{tabular}{ccccc}
\hline Coating Style & $\begin{array}{c}\text { Absolute } \\
\text { Temperature (K) }\end{array}$ & $\boldsymbol{K} \mathbf{~ m g}^{\mathbf{2} \mathbf{c m}^{-\mathbf{4}} \mathbf{t}^{-\mathbf{1}} \text { ) }}$ & $\begin{array}{c}\boldsymbol{R}^{\mathbf{2}} \text { (Correlation } \\
\text { Coefficient) }\end{array}$ & $\boldsymbol{E}_{\mathbf{a}}$ (KJ mol-1) \\
\hline $\mathrm{ZrO}_{2}$ & 873.15 & $9.88 \times 10^{-8}$ & 0.99 & 140.87 \\
$t_{\mathrm{TiB}_{2}}: t_{\mathrm{ZrO}_{2}}=2: 1$ & 873.15 & $4.58 \times 10^{-6}$ & 0.99 & 107.34 \\
$t_{\mathrm{TiB}_{2}}: t_{\mathrm{ZrO}_{2}}=3: 1$ & 873.15 & $1.25 \times 10^{-5}$ & 0.99 & 98.60 \\
$t_{\mathrm{TiB}_{2}}: t_{\mathrm{ZrO}_{2}}=4: 1$ & 873.15 & $1.67 \times 10^{-5}$ & 0.99 & 96.07 \\
$t_{\mathrm{TiB}_{2}}: t_{\mathrm{ZrO}_{2}}=5: 1$ & 873.15 & $4.52 \times 10^{-5}$ & 0.99 & 87.34 \\
$t_{\mathrm{TiB}_{2}}: t_{\mathrm{ZrO}_{2}}=6: 1$ & 873.15 & $6.05 \times 10^{-5}$ & 0.98 & 76.83 \\
$\mathrm{TiB}_{2}$ & 873.15 & $1.51 \times 10^{-5}$ & 0.98 & \\
\hline
\end{tabular}

Table 1 shows the $E_{\mathrm{a}}$ values for the oxidation of the $\mathrm{TiB}_{2}$ and $\mathrm{ZrO}_{2}$ monolayers and the $\mathrm{TiB}_{2} / \mathrm{ZrO}_{2}$ multilayers. The $E_{\mathrm{a}}$ values for the oxidation of the $\mathrm{TiB}_{2}$ and $\mathrm{ZrO}_{2}$ monolayers were approximately 76.84 and $140.87 \mathrm{~kJ} / \mathrm{mol}$, respectively, indicating that the $\mathrm{ZrO}_{2}$ monolayers were less likely to react with oxygen compared to the $\mathrm{TiB}_{2}$ monolayers under the same conditions. For the multilayers, $E_{\mathrm{a}}$ decreased 
with increasing modulation ratio, and the $E_{\mathrm{a}}$ values were higher than that of the $\mathrm{TiB}_{2}$ monolayer. Discontinuous oxidation retarded the inward diffusion of oxygen and hindered the outward diffusion of metallic components. The formation of a dense (Ti, B)-oxide scale and the internally inserted $\mathrm{ZrO}_{2}$ layers in the $\mathrm{TiB}_{2} / \mathrm{ZrO}_{2}$ multilayers enhanced the oxidation resistance of the multilayers $[7,38]$.

To verify the synergetic enhancement of the oxidation resistance and mechanical properties, the hardness, residual stress (Figure 7a), and elastic modulus (Figure $7 \mathrm{~b}$ ) of the $\mathrm{TiB}_{2}$ and $\mathrm{ZrO}_{2}$ monolayers and the $\mathrm{TiB}_{2} / \mathrm{ZrO}_{2}$ multilayers were measured before and after annealing. The higher $\mathrm{TiB}_{2}$ fraction with increasing ratio from 2:1 to 6:1 the hardness increased. It almost followed the rule of mixture of the individual components [39] Herein, with increasing $t_{\mathrm{TiB}_{2}}: t_{\mathrm{ZrO}_{2}}$, the hardness and elastic modulus both improved, reaching their highest values of $23.9 \mathrm{GPa}$ and $303.1 \mathrm{GPa}$ before annealing. Accordingly, Figure $7 \mathrm{~b}$ shows a decrease in hardness and elastic modulus after oxidation. The hardness reduction during oxidation was basically due to the decreasing fraction of $\mathrm{TiB}_{2}$. The reduction in residual stress also caused by high-temperature oxidation results in reduced hardness [40]. After annealing at $600{ }^{\circ} \mathrm{C}$, the hardness of the oxidized multilayers did not increase as the oxidation resistance of the multilayers did. Instead, a critical point appears at $t_{\mathrm{TiB}_{2}}: t_{\mathrm{ZrO}_{2}}=4: 1$, where both the hardness and elastic modulus reach their maximum values of approximately $16.4 \mathrm{GPa}$ and $262.4 \mathrm{GPa}$. These values are much higher than those of the $\mathrm{TiB}_{2}$ monolayers. In addition, among the multilayers, annealing resulted in the smallest reductions in hardness and elastic modulus for the multilayer with $t_{\mathrm{TiB}_{2}}: t_{\mathrm{ZrO}_{2}}=4: 1$ (Figure $7 \mathrm{~b}$ ).

(a)

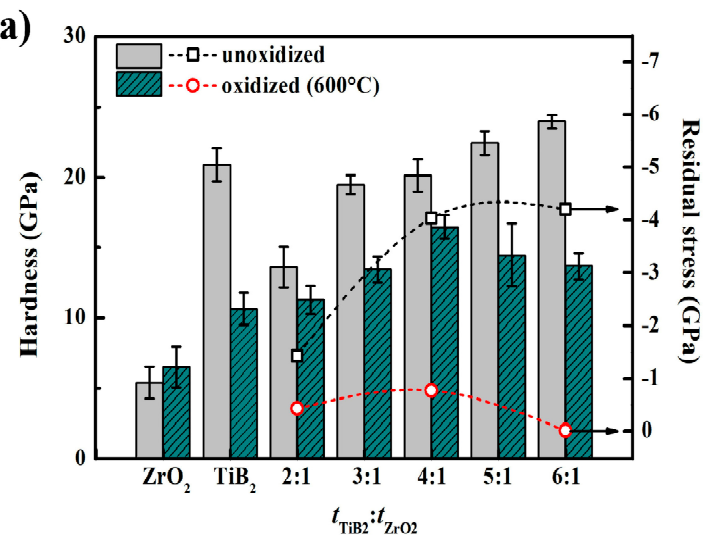

(b)

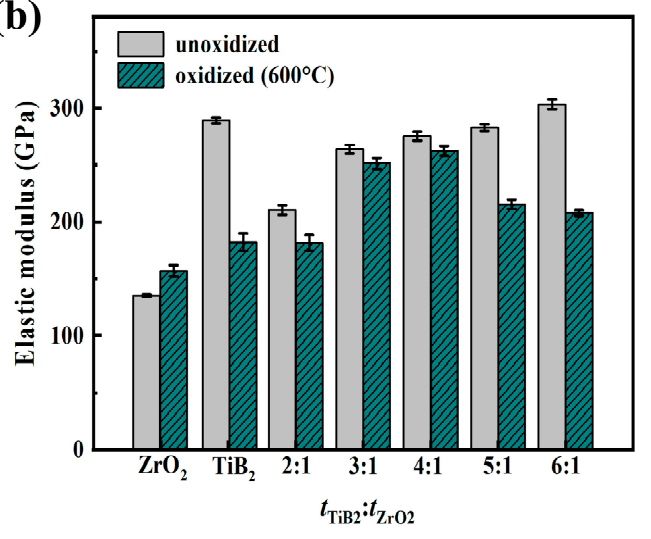

Figure 7. The hardnes, residual stress (a), and elastic modulus (b) of the $\mathrm{TiB}_{2}$ and $\mathrm{ZrO}_{2}$ monolayers and the $\mathrm{TiB}_{2} / \mathrm{ZrO}_{2}$ multilayers with different $t_{\mathrm{TiB}_{2}}: t_{\mathrm{ZrO}_{2}}$ before and after annealing.

Figure 8 shows the results of scratch scan and post scan surface profiles of $\mathrm{TiB}_{2}$ monolayers and $\mathrm{TiB}_{2} / \mathrm{ZrO}_{2}\left(t_{\mathrm{TiB}_{2}}: t_{\mathrm{ZrO}_{2}}=4: 1\right)$ multilayers before and after annealing. The maximum load was $5 \mathrm{~N}$. The critical fracture load can be used to characterize the adhesion strength or fracture resistance of the coating. The loads of first cracking for the $\mathrm{TiB}_{2}$ monolayers and $\mathrm{TiB}_{2} / \mathrm{ZrO}_{2}\left(t_{\mathrm{TiB}_{2}}: t_{\mathrm{ZrO}_{2}}=4: 1\right)$ multilayers before annealing were 4.17 and $4.02 \mathrm{~N}$, respectively. Meanwhile, only slight cracks were observed at the edges of the coatings, and they did not delaminate with the tracks, indicating the good strengths of the $\mathrm{TiB}_{2}$ monolayers and $\mathrm{TiB}_{2} / \mathrm{ZrO}_{2}\left(t_{\mathrm{TiB}_{2}}: t_{\mathrm{ZrO}_{2}}=4: 1\right)$ multilayers on the substrates. Owing to the formation of oxidation products and the oxidation of the interface to the substrate itself, the critical fracture load of $\mathrm{TiB}_{2} / \mathrm{ZrO}_{2}\left(t_{\mathrm{TiB}_{2}}: t_{\mathrm{ZrO}_{2}}=4: 1\right)$ multilayers $(3.91 \mathrm{~N})$ was higher than the $\mathrm{TiB}_{2}$ monolayers $(3.14 \mathrm{~N})$ after annealing, and the fracture range was smaller. This indicated that the $\mathrm{TiB}_{2} / \mathrm{ZrO}_{2}\left(t_{\mathrm{TiB}_{2}}: t_{\mathrm{ZrO}_{2}}=4: 1\right)$ multilayers enhances the adhesion strength with the substrate and is in favor of releasing the residual stress.

Our experimental observations showed that the oxidation resistance of the multilayers increased as the modulation ratio decreased. That is, as the $\mathrm{ZrO}_{2}$ layers became thicker, the progressive oxidation of the multilayers from top to bottom became more difficult. The change in hardness with annealing was studied based on the proposed oxidation mechanism, which takes into account changes in the mechanical properties of the layers due to oxidation and the development of internal stresses to 
accommodate the volume increase associated with the oxidation of multilayers during annealing. The hardness of the annealed multilayers should also increase as the modulation ratio decrease. The experimental results did not indicate a further increase in hardness for the multilayers with $t_{\mathrm{TiB}_{2}}: t_{\mathrm{ZrO}_{2}}=4: 1$. This behavior was associated with the development of damage at the interfaces between the $\mathrm{ZrO}_{2}$ and $\mathrm{TiB}_{2}$ layers, and the corresponding rule of mixtures for composites. The construction of the multilayer system with controlled $\mathrm{ZrO}_{2}$ content provided a multilayer structure with good oxidation resistance while maintaining a high hardness.

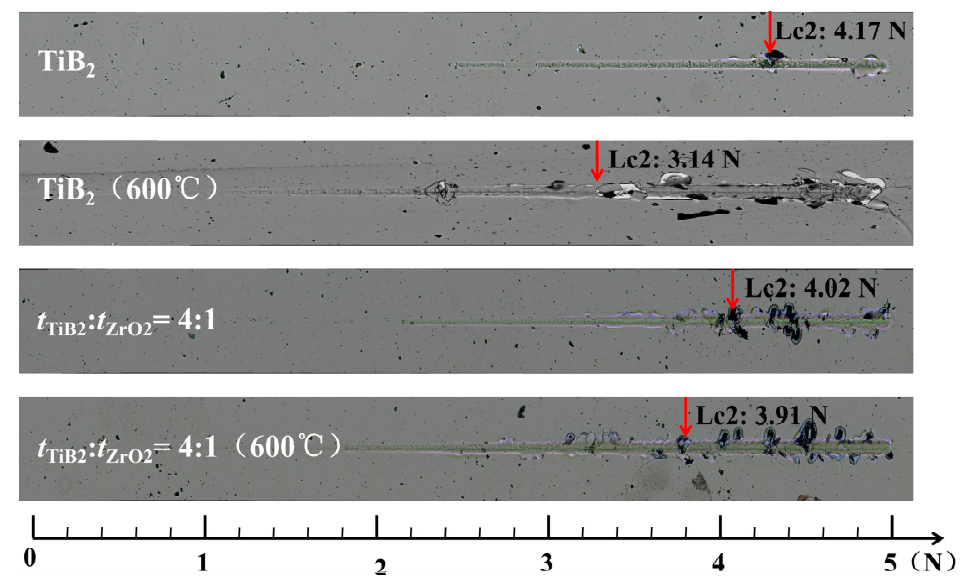

Figure 8. Scratch track images of $\mathrm{TiB}_{2}$ monolayers and $\mathrm{TiB}_{2} / \mathrm{ZrO}_{2}\left(t_{\mathrm{TiB}_{2}}: t_{\mathrm{ZrO}_{2}}=4: 1\right)$ multilayers before and after annealing.

\section{Conclusions}

In this work, $\mathrm{TiB}_{2} / \mathrm{ZrO}_{2}$ multilayers with a constant modulation period along with $\mathrm{TiB}_{2}$ and $\mathrm{ZrO}_{2}$ monolayers for comparison were synthesized on $\mathrm{Si}(100)$ substrates by magnetron sputtering. The oxidation behaviors of the samples upon annealing at $600{ }^{\circ} \mathrm{C}$ were investigated. The deposited multilayers were dense and maintained their periodic structures after annealing. The oxidation resistance and mechanical properties of the multilayers before and after high-temperature oxidation were studied based on an oxidation mechanism model. The $\mathrm{TiB}_{2} / \mathrm{ZrO}_{2}$ multilayers exhibited a significantly higher $E_{\mathrm{a}}$ for oxidation $(\sim 107.34 \mathrm{~kJ} / \mathrm{mol})$ than $\mathrm{TiB}_{2}$ monolayer $(\sim 76.84 \mathrm{~kJ} / \mathrm{mol})$. The maximum hardness (16.4 GPa) and elastic modulus $(262.4 \mathrm{GPa})$ of the oxidized multilayers were observed at $t_{\mathrm{TiB}_{2}}: t_{\mathrm{ZrO}_{2}}=4: 1$. The superior mechanical properties and oxidation resistance of the $\mathrm{TiB}_{2} / \mathrm{ZrO}_{2}$ multilayers were attributed to the synergistic contributions of the modulated thickness of the $\mathrm{TiB}_{2}$ and $\mathrm{ZrO}_{2}$ layers and the discontinuous oxidation of the multilayers. The findings of this work demonstrate that ceramics/metal oxide nanocomposites with enhanced oxidation resistance and mechanical properties can be obtained via structural optimization.

Author Contributions: Conceptualization, D.L.; data curation, Y.X.; formal analysis, L.D.; investigation, D.M., L.D. and J.W.; methodology, D.M., L.D. and D.L.; project administration, D.M., Y.X., M.Z. and D.L.; resources, J.W.; writing - original draft preparation, D.M.; writing - review and editing, L.D., J.W. and D.L.

Funding: This research was funded by the National Natural Science Foundation of China (No. 51772209, 51901158), Tianjin Science and Technology Project (Nos. 18PTZWHZ00020, 18JCQNJC72000, 18JCQNJC73400), and Program for Innovative Research in University of Tianjin (No. TD13-5077). This work was also supported by the Science \& Technology Development Fund of Tianjin Education Commission for Higher Education (No. 2018KJ158).

Conflicts of Interest: The authors declare no conflict of interest. 


\section{References}

1. Monclus, M.A.; Callisti, M.; Polcar, T.; Yang, L.W.; Llorca, J.; Molina-Aldareguia, J.M. Selective oxidation-induced strengthening of $\mathrm{Zr} / \mathrm{Nb}$ nanoscale multilayers. Acta Mater. 2017, 122, 1-10. [CrossRef]

2. Cho, S.; Jo, I.; Lee, Y.-H.; Yoo, Y.W.; Byon, E.; Lee, S.-K.; Lee, S.-B. Highly improved oxidation resistance of TiC-SKD11 composite by SiC/TiB 2 based hybrid coating. Appl. Surf. Sci. 2018, 448, 407-415. [CrossRef]

3. Shimada, S.; Takahashi, M.; Kiyono, H.; Tsujino, J. Coatings and microstructures of monolithic TiB ${ }_{2}$ films and double layer and composite $\mathrm{TiCN} / \mathrm{TiB}_{2}$ films from alkoxide solutions by thermal plasma CVD. Thin Solid Films 2008, 516, 6616-6621. [CrossRef]

4. Ma, A.; Jiang, M. The Study on oxidative dynamic of $\mathrm{TiB}_{2}$ ceramic. Ceramics 2006, 7, 19-21. (In Chinese) [CrossRef]

5. Mokhayer, M.M.; Kakroudi, M.G.; Milani, S.S.; Ghiasi, H.; Vafa, N.P. Investigation of AlN addition on the microstructure and mechanical properties of $\mathrm{TiB}_{2}$ ceramics. Ceram. Int. 2019, 45, 16577-16583. [CrossRef]

6. Zhirkov, I.; Petruhins, A.; Naslund, L.-A.; Kolozsvári, S.; Polcik, P.; Rosen, J. Vacuum arc plasma generation and thin film deposition from a $\mathrm{TiB}_{2}$ cathode. Appl. Phys. Lett. 2015, 107, 184103. [CrossRef]

7. Li, H.; Sun, Y.; Zhang, J. Effect of $\mathrm{ZrO}_{2}$ particle on the performance of micro-arc oxidation coatings on Ti6Al4V. Appl. Surf. Sci. 2015, 342, 183-190. [CrossRef]

8. Moon, J.; Choi, H.; Kim, H.; Lee, C. The effects of heat treatment on the phase transformation behavior of plasma-sprayed stabilized $\mathrm{ZrO}_{2}$ coatings. Surf. Coat. Technol. 2002, 155, 1-10. [CrossRef]

9. Mahnicka-Goremikina, L.; Svinka, R.; Svinka, V. Influence of $\mathrm{ZrO}_{2}$ and $\mathrm{WO}_{3}$ doping additives on the thermal properties of porous mullite ceramics. Ceram. Int. 2018, 44, 16873-16879. [CrossRef]

10. Li, Y.; Li, J.; Liang, R.; Zhao, R.; Xiong, B.; Liu, H.; Tian, H.; Yang, Y.; Ren, T.-L. Switching dynamics of ferroelectric $\mathrm{HfO}_{2}-\mathrm{ZrO}_{2}$ with various $\mathrm{ZrO}_{2}$ contents. Appl. Phys. Lett. 2019, 114, 142902. [CrossRef]

11. Ramana, C.V.; Vemuri, R.S.; Fernandez, I.; Campbell, A.L. Size-effects on the optical properties of zirconium oxide thin films. Appl. Phys. Lett. 2009, 95, 231905. [CrossRef]

12. Yao, J.; He, Y.; Wang, D.; Lin, J. High-temperature oxidation resistance of $\left(\mathrm{Al}_{2} \mathrm{O}_{3}-\mathrm{Y}_{2} \mathrm{O}_{3}\right) /\left(\mathrm{Y}_{2} \mathrm{O}_{3}\right.$-stabilized $\mathrm{ZrO}_{2}$ ) laminated coating on $8 \mathrm{Nb}-\mathrm{TiAl}$ alloy prepared by a novel spray pyrolysis. Corrosion Sci. 2014, 80, 19-27. [CrossRef]

13. Guo, C.; Zhou, J.; Chen, J.; Zhao, J.; Yu, Y.; Zhou, H. Improvement of the oxidation and wear resistance of pure Ti by laser cladding at elevated temperature. Surf. Coat. Technol. 2010, 205, 2142-2151. [CrossRef]

14. Ryabchikov, A.I.; Kashkarov, E.B.; Pushilina, N.S.; Syrtanov, M.S.; Shevelev, A.E.; Korneva, O.S.; Sutygina, A.N.; Lider, A.M. High-intensity low energy titanium ion implantation into zirconium alloy. Appl. Surf. Sci. 2018, 439, 106-112. [CrossRef]

15. Wu, H.; Zhang, P.; Zhao, H.; Wang, L.; Xie, A. Effect of different alloyed layers on the high temperature oxidation behavior of newly developed $\mathrm{Ti}_{2} \mathrm{AlNb}$-based alloys. Appl. Surf. Sci. 2011, 257, 1835-1839. [CrossRef]

16. Li, G.; Li, Y.; Li, G. Coherent growth and superhardness effect in $\mathrm{VC} / \mathrm{Si}_{3} \mathrm{~N}_{4}$ nanomultilayers. Surf. Coat. Technol. 2011, 205, 3881-3884. [CrossRef]

17. Fu, T.; Zhang, Z.; Peng, X.; Weng, S.; Miao, Y.; Zhao, Y.; Fu, S.; Hu, N. Effects of modulation periods on mechanical properties of V/VN nano-multilayers. Ceram. Int. 2019, 45, 10295-10303. [CrossRef]

18. Yin, D.; Peng, X.; Qin, Y.; Wang, Z. Template effect in TiN/AlN multilayered coatings from first principles. Ceram. Int. 2015, 41, 10095-10101. [CrossRef]

19. Shah, S.A.; Khan, A.F.; Khan, A.; Rahim, N.A.; Mehmood, M. Multilayer Si/Ge thin films with quantum confinement effects for photovoltaic applications. Appl. Surf. Sci. 2014, 296, 185-188. [CrossRef]

20. Yang, F.J.; Wang, H.; Wang, H.B.; Cao, X.; Li, Q.; Zhou, M.J. Effect of interfacial diffusion on microstructure and properties of FePt/B ${ }_{4} \mathrm{C}$ multifunctional multilayer composite films. Appl. Surf. Sci. 2008, 254, 2516-2520. [CrossRef]

21. Pan, Y.; Lei, D.; Na, L.; Yu, J.; Li, C.; Li, D. Investigating the influence of epitaxial modulation on the evolution of superhardness of the VN/TiB 2 multilayers. Appl. Surf. Sci. 2016, 390, 406-411. [CrossRef]

22. Junhua, X.; Geyang, L.; Mingyuan, G. The microstructure and mechanical properties of TaN/TiN and TaWN/TiN superlattice films. Thin Solid Films 2000, 370, 45-49. [CrossRef] 
23. Saladukhin, I.A.; Abadias, G.; Uglov, V.V.; Zlotski, S.V.; Michel, A.; Janse van Vuuren, A. Thermal stability

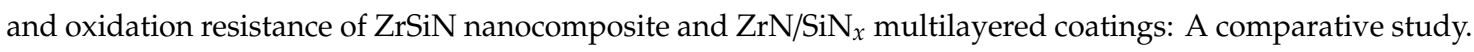
Surf. Coat. Technol. 2017, 332, 428-439. [CrossRef]

24. Yao, X.; Li, H.; Zhang, Y.; Ren, J.; Yao, D.; Tao, J. A SiC/ZrB $2-S i C / S i C$ oxidation resistance multilayer coating for carbon/carbon composites. Corrosion Sci. 2012, 57, 148-153. [CrossRef]

25. Lei, Z.; Liu, Y.; Fei, M.; Song, Z.; Li, Y. Oxidation resistance of TiAlN/ZrN multilayer coatings. Vacuum 2016, 127, 22-29. [CrossRef]

26. Janssen, G.C.A.M.; Abdalla, M.M.; van Keulen, F.; Pujada, B.R.; van Venrooy, B. Celebrating the 100th anniversary of the Stoney equation for film stress: developments from polycrystalline steel strips to single crystal silicon wafers. Thin Solid Films 2009, 517, 1858-1867. [CrossRef]

27. Legoues, F.K.; Mooney, P.M.; Tersoff, J. Measurement of the activation barrier to nucleation of dislocations in thin films. Phys. Rev. Lett. 1993, 71, 396-399. [CrossRef] [PubMed]

28. Xu, X.; Sheng, X.L.; Zhang, T.F.; Liu, M.; Xin, X.L. Raman spectrum and friction behaviors of carbon-doped $\mathrm{TiB}_{2}$ films prepared by magnetron sputtering. J. Mater. Eng. 2012, 2, 30-32. [CrossRef]

29. Bondarev, A.V.; Kiryukhantsev-Korneev, P.V.; Levashov, E.A.; Shtansky, D.V. Tribological behavior and self-healing functionality of TiNbCN-Ag coatings in wide temperature range. Appl. Surf. Sci. 2017, 396, 110-120. [CrossRef]

30. Maniu, D.; Iliescu, T.; Ardelean, I.; Cinta-Pinzaru, S.; Tarcea, N.; Kiefer, W. Raman study on $\mathrm{B}_{2} \mathrm{O}_{3}-\mathrm{CaO}$ glasses. J. Mol. Struct. 2003, 651-653, 485-488. [CrossRef]

31. Song, Y.; Zheng, X.; Yu, G.; Zhao, J.; Jiang, L.; Liu, Y.; Yang, B.; Yang, Y. The characteristics of laser-driven shock wave investigated by time-resolved Raman spectroscopy. J. Raman Spectrosc. 2011, 42, 345-348. [CrossRef]

32. Tampieri, A.; Bellosi, A. Oxidation of monolithic $\mathrm{TiB}_{2}$ and of $\mathrm{Al}_{2} \mathrm{O}_{3}-\mathrm{TiB}_{2}$ composite. J. Mater. Sci. 1993, 28, 649-653. [CrossRef]

33. Tao, G.; He, J.; Pang, X.; Volinsky, A.A.; Su, Y.; Qiao, L. High temperature brittle film adhesion measured from annealing-induced circular blisters. Acta Mater. 2017, 138, 1-9. [CrossRef]

34. Liang, B.; Chen, H. Overview of the application and development of $\mathrm{ZrO}_{2}$ coatings (films). Bull. Chin. Ceram. Soc. 2003. (In Chinese) [CrossRef]

35. Dang, C.; Li, J.; Wang, Y.; Chen, J. Structure, mechanical and tribological properties of self-toughening TiSiN/Ag multilayer coatings on Ti6Al4V prepared by arc ion plating. Appl. Surf. Sci. 2016, 386, 224-233. [CrossRef]

36. Xiao, B.; Li, H.; Mei, H.; Dai, W.; Zuo, F.; Wu, Z.; Wang, Q. A study of oxidation behavior of AlTiN- and AlCrN-based multilayer coatings. Surf. Coat. Technol. 2018, 333, 229-237. [CrossRef]

37. Xu, Y.X.; Riedl, H.; Holec, D.; Li, C.; Yong, D.; Mayrhofer, P.H. Thermal stability and oxidation resistance of sputtered Ti-Al-Cr-N hard coatings. Surf. Coat. Technol. 2017, 324, 48-56. [CrossRef]

38. Dong, K.F.; Li, H.H.; Peng, Y.G.; Ju, G.; Chow, G.M.; Chen, J.S. L1 $1_{0} \mathrm{FePt}-\mathrm{ZrO}_{2}$ (001) nanostructured films with high aspect ratio columnar grains. Appl. Phys. Lett. 2014, 104, 192404. [CrossRef]

39. Sarkar, B.K.; Mukherjee, M.K.; Natarajan, A. A modification of the rule of mixture in estimating strengths of a composite. Mater. Sci. Eng. Technol. 1982, 13, 269-273. [CrossRef]

40. Bouaouina, B.; Besnard, A.; Abaidia, S.E.; Haid, F. Residual stress, mechanical and microstructure properties of multilayer $\mathrm{Mo}_{2} \mathrm{~N} / \mathrm{CrN}$ coating produced by R.F Magnetron discharge. Appl. Surf. Sci. 2017, 395, 117-121. [CrossRef]

(C) 2019 by the authors. Licensee MDPI, Basel, Switzerland. This article is an open access article distributed under the terms and conditions of the Creative Commons Attribution (CC BY) license (http://creativecommons.org/licenses/by/4.0/). 